\title{
PACTOS DE UMA RACIONALIDADE POLÍTICA, PRÁTICAS SOLIDÁRIAS NA ESCOLA INCLUSIVA: MODOS DE SUBJETIVAÇÃO DOCENTE ${ }^{1}$
}

\author{
PACTS OF A POLITICAL RATIONALITY, SUPPORTIVE PRACTICES IN INCLUSIVE \\ SCHOOLS: MODES OF TEACHER SUBJECTIVATION
}
PACTOS DE UNA RACIONALIDAD POLÍTICA, PRÁCTICAS SOLIDARIAS EN LA ESCUELA INCLUSIVA: MODOS DE SUBJETIVACIÓN DE PROFESORES

\author{
Márcia Lise Lunardi Lazzarin ${ }^{1}$ \\ Simoni Timm Hermes ${ }^{2}$
}

\begin{abstract}
RESUMO
No cruzamento da Educação Inclusiva com a Educação Especial, este artigo objetiva problematizar o modelo ideal de professor produzido por meio das práticas solidárias no processo de formação docente na Educação Especial no Brasil. Para tal, a materialidade de pesquisa contempla materiais didáticos relacionados à Rede Nacional de Formação Continuada de Professores na Educação Especial. A partir dos Estudos Foucaultianos em Educação, desenvolveu-se um exercício analítico em torno da materialidade da pesquisa, tendo-se optado pelo uso da ferramenta governamentalidade. Conclui-se, diante dos dados produzidos, que a mesma racionalidade política neoliberal, esta que serve como referência para a biopolítica e que promove o empresariamento de si na docência, opera na produção de práticas solidárias na escola inclusiva a fim de garantir o sucesso da inclusão escolar. A docência como prática solidária torna-se o modelo ideal para a escola inclusiva.
\end{abstract}

PALAVRAS-CHAVE: Governamentalidade. Neoliberalismo. Docência. Solidariedade.

\begin{abstract}
In the intersection between Inclusive Education and Special Education, this paper aims to problematize the ideal model of teacher produced by means of supportive practices in the process of teacher education in Special Education in Brazil. In order to achieve this aim, the materiality of research includes textbooks related to the National Network of Continuing Teacher Education in Special Education. From the Foucauldian studies in Education, an analytical exercise was developed around the materiality of the research, with the use of the "governmentality" tool. Given the data produced, it is concluded that the very neoliberal political rationality that serves as a reference for bio-politics and promotes teacher self-entrepreneurship also operates in the production of supportive practices in inclusive schools to ensure the success of inclusive education. Teaching as a supportive practice becomes the ideal model to inclusive school.
\end{abstract}

KEYWORDS: Governmentality. Neoliberalism. Teaching. Solidarity.

\footnotetext{
${ }^{1}$ Doutora em Educação - Universidade Federal do Rio Grande do Sul (UFRGS) - Porto Alegre, RS - Brasil. Professora Associada do Departamento de Educação Especial, do Centro de Educação - Universidade Federal de Santa Maria (UFSM) - Santa Maria, RS - Brasil. Professora credenciada no Programa de Pós-Graduação em Educação, na Linha de pesquisa: Educação Especial. E-mail: lunazza@gmail.com

${ }^{2}$ Doutoranda em Educação - Universidade Federal de Santa Maria (UFSM) - Santa Maria, RS - Brasil. Pedagoga do Centro de Tecnologia - Universidade Federal de Santa Maria (UFSM) - Santa Maria, RS - Brasil - Professora Externa do Curso de Educação Especial - Licenciatura (a distância) - Universidade Federal de Santa Maria (UFSM) - Santa Maria, RS - Brasil. E-mail: simoni.hermes@ufsm.br
}

Submetido em: 24/03/2016 - Aceito em: 31/03/2017

(C) ETD-Educação Temática Digital Campinas, SP v.19 n.3 p. 000-000 jul./set. 2017




\section{RESUMEN}

En la intersección de la Educación Inclusiva con la Educación Especial, este artículo pretende problematizar el modelo de profesor ideal producido a través de prácticas de solidaridad en proceso de formación de los profesores en la educación especial en Brasil. Con este fin, la materialidad de investigación incluye materiales educativos relacionados con la Red Nacional de Formación Continua de Profesores en Educación Especial. Con base en los estudios Foucaultianos en Educación, desarrollado un ejercicio analítico en torno a la materialidad de la investigación, y optó por el uso de la herramienta de la gubernamentalidad. Se desprende de los datos producidos que la misma racionalidad política neoliberal que sirve como referencia para la biopolítica y promueve el espíritu empresarial en la enseñanza también opera en la producción de prácticas solidarias en la escuela inclusiva para garantizar el éxito de la inclusión escolar. La enseñanza como práctica de la solidaridad se convierte en el modelo ideal para las escuelas inclusivas.

PALABRAS CLAVE: Gubernamentalidad. Neoliberalismo. Enseñanza. Solidaridad.

\section{ESCOLA INCLUSIVA NA CENTRALIDADE DA PROBLEMATIZAÇÃO: MOVIMENTOS DA PESQUISA}

Nas últimas décadas, a inclusão escolar dos alunos com necessidades educacionais especiais nas escolas regulares tem materializado o cruzamento entre a Educação Inclusiva e a Educação Especial por meio do Atendimento Educacional Especializado (AEE). Este serviço, constituído como o conjunto de atividades e de recursos de acessibilidade e pedagógicos desenvolvidos nas escolas comuns/regulares/inclusivas para complementar ou suplementar a formação dos alunos com deficiência, transtornos globais do desenvolvimento e altas habilidades/superdotação, conforme a Política Nacional de Educação Especial na Perspectiva da Educação Inclusiva, publicada em 2008, o Decreto no 7.611 de 17 de novembro de 2011, a Resolução no 4, de 02 de outubro de 2009 e o Parecer CNE/CEB no 13, de 03 de junho de 2009, colabora para os investimentos na formação continuada dos professores do AEE na agenda nacional. Os professores que atuam nas salas de recursos multifuncionais, espaços-tempos dotados de equipamentos de informática, mobiliários, materiais didático-pedagógicos e de acessibilidade voltados ao público-alvo da Educação Especial, devem fazer cursos de Atendimento Educacional Especializado, cursos estes ofertados como especialização, aperfeiçoamento ou extensão. Nesse movimento, inscrevemos este artigo.

Derivado de uma pesquisa concluída em nível de pós-graduação, este artigo objetiva problematizar o modelo ideal de professor produzido por meio de práticas solidárias no processo de formação docente na Educação Especial no Brasil. Com base nos Estudos Foucaultianos em Educação, utiliza-se especificamente a ferramenta governamentalidade, além das contribuições da Teoria do Capital Humano, de Theodore Schultz, para desenvolver um exercício analítico sobre a racionalidade política envolvida com a produção de uma subjetividade docente na Educação Especial. Para tal, como materialidade de pesquisa, utilizamos fascículos da Coleção $A$ Educação Especial na Perspectiva da Inclusão Escolar, publicada pela Secretaria de Educação Especial (SEESP) em parceria com a 
Universidade Federal do Ceará (UFC), no ano de 2010, relacionados à Rede Nacional de Formação Continuada de Professores na Educação Especial no nosso país.

A referida Coleção conta com dez fascículos. De maneira geral, o primeiro fascículo, "A escola comum inclusiva", trata das noções de identidade e diferença na escola inclusiva, explora o AEE na articulação entre a escola regular e a Educação Especial e apresenta as salas de recursos multifuncionais e o trabalho com os alunos da Educação Especial nesse espaço-tempo. Os demais fascículos referem-se às especificidades do campo da Educação Especial. Eles estão compostos basicamente pela identificação do desvio (deficiência intelectual, baixa visão e cegueira, surdez, surdocegueira, deficiência múltipla, deficiência física, transtornos globais do desenvolvimento, altas habilidades/superdotação), pelos recursos a serem utilizados com esses sujeitos no AEE e por estudos de caso, planos de trabalho ou, às vezes, exemplos de práticas escolares. Desses materiais didáticos, três referem-se aos recursos clínicos e pedagógicos destinados a diferentes áreas do desvio: "Recursos pedagógicos acessíveis e comunicação aumentativa e alternativa", "Orientação e mobilidade, adequação postural e acessibilidade espacial" e "Livro acessível e informática acessível".

Esses materiais didáticos relacionados à Rede Nacional veiculam, portanto, os conhecimentos, os recursos, as técnicas e as atitudes a serem desenvolvidas pelo docente do AEE para a escola inclusiva. Neste artigo, trazemos recorrências e singularidades discursivas dos seguintes fascículos: "A escola comum inclusiva" (ROPOLI, 2010); "Surdocegueira e deficiência múltipla" (BOSCO, 2010); "Recursos pedagógicos acessíveis e comunicação aumentativa e alternativa" (SARTORETTO, 2010) e "Orientação e mobilidade, adequação postural e acessibilidade espacial" (GIACOMINI, 2010). Essas recorrências e as singularidades discursivas focam aquilo que, no processo formativo, comporta maneiras de ser e estar docente que colaborem com a racionalidade política implicada na escola inclusiva, dentre outras, a docência como prática solidária.

Considerando o exposto, na seção que segue, "Dos pactos da racionalidade política neoliberal: contextos da formação docente em Educação Especial", discorremos sobre a racionalidade política neoliberal norte-americana e as possíveis relações com a formação docente em Educação Especial. Na seção "Das práticas solidárias na escola inclusiva: a docência pelo Atendimento Educacional Especializado", mostramos que, mesmo investindo no empresariamento de si, a formação dos professores do AEE sistematiza práticas solidárias na escola regular a fim de efetivar o sucesso da inclusão escolar dos alunos com necessidades educacionais especiais.

\section{DOS PACTOS DA RACIONALIDADE POLÍTICA NEOLIBERAL: CONTEXTOS DA FORMAÇÃO DOCENTE EM EDUCAÇÃO ESPECIAL}

Na aula de 1 ㅇ de fevereiro de 1978, do Curso "Segurança, território e população" (2008a), Foucault toma o governo como uma problemática própria do século XVI que, ao longo dos anos, modifica suas ênfases em relação à condução da conduta dos homens. 
Assim, inicialmente, o problema do governo envolvia o governo de si, o governo das almas e das condutas, o governo dos filhos e o governo dos Estados pelos príncipes, entre outras formas e outros aspectos. Neste momento, tendo como referência os últimos estudos foucaultianos, relativos à biopolítica, interessa-nos abordar a problemática do governo pela figura do Estado, um Estado que não está desde sempre aí, mas que, sendo produzido em diferentes modos, parece inevitável.

\begin{abstract}
Como quer que seja, através de todos esses sentidos, há algo que aparece claramente: nunca se governa um Estado, nunca se governa um território, nunca se governa uma estrutura política. (...) Não é portanto a cidade como estrutura política, mas as pessoas, indivíduos ou coletividade. Os homens é que são governados. (...) Os que são governados, portanto, inicialmente, fundamentalmente, pelo menos através dessa primeira pesquisa, são os homens (FOUCAULT, 2008a, p.164-165).
\end{abstract}

Por isso, sinalizando o governamento dos homens, dissertaremos sobre a formação de professores de Educação Especial na perspectiva da Educação Inclusiva, sendo essa formação de professores vinculada às práticas governamentais pela razão de Estado. Isso porque, a partir de Foucault (2008a, p.369),

não se pode falar do Estado-coisa como se fosse um ser que se desenvolve a partir de si mesmo e que se impõe por uma mecânica espontânea, como que automática, aos indivíduos. O Estado é uma prática. O Estado não pode ser dissociado do conjunto das práticas que fizeram efetivamente que ele se tornasse uma maneira de governar, uma maneira de agir, uma maneira também de se relacionar com o governo.

A razão de Estado refere-se a essa racionalidade que se coloca como instrumento de inteligibilidade e estratégia nas práticas de governamento, especificamente, pela emergência de um Estado governamentalizado. No caso deste artigo, trata-se da racionalidade política neoliberal e da produtividade desta na formação continuada de professores na Educação Especial no Brasil. Ressaltamos que, para tratar dessa formação de professores na Educação Especial, utilizaremos os registros dos cursos de graduação ofertados pela Universidade Federal de Santa Maria (UFSM), uma vez que esta Instituição Federal de Ensino Superior foi pioneira na oferta de cursos de graduação em Educação Especial no Estado do Rio Grande do Sul e no Brasil.

Entendemos que os programas de formação inicial e continuada fomentados pela política nacional de formação de professores no nosso país, especificamente os vinculados à Diretoria de Políticas de Educação Especial na Secretaria de Educação Continuada, Alfabetização, Diversidade e Inclusão do Ministério da Educação, parecem regidos pela mecânica de um poder que insiste em "fazer viver" e por uma política sobre a vida. Esse poder - o biopoder - desenvolveu-se mediante dois polos principais, conforme Foucault (2001). O primeiro polo, denominado anátomo-política do corpo humano, formou-se em meados do século XVII e centrou-se no corpo como máquina, capaz de ser produzido no registro da obediência e da utilidade pela operação da disciplina. O segundo polo, nomeado de uma biopolítica da população, formou-se a partir da metade do século XVIII, contrário ao 
direito de morte do soberano, explicado pela teoria clássica de soberania como direito de espada, e

\footnotetext{
centrou-se no corpo-espécie, no corpo transpassado pela mecânica do ser vivo e como suporte dos processos biológicos: a proliferação, os nascimentos e a mortalidade, o nível de saúde, a duração da vida, a longevidade, com todas as condições que podem fazê-los variar; tais processos são assumidos mediante toda uma série de intervenções e contrôles reguladores (FOUCAULT, 2001, p. 131).
}

Nesse contexto, o biopoder constitui-se pela entrada da vida, do homem como "uma espécie viva num mundo vivo" (FOUCAULT, 2001, p. 135), dos fenômenos ou dos processos biológicos na história; a biopolítica trata das estratégias específicas e práticas para regulamentar essa vida do corpo-espécie, da população, "uma massa global, afetada por processos de conjunto que são próprios da vida, que são processos como o nascimento, a morte, a produção, a doença, etc." (FOUCAULT, 2005, p. 289). Os conceitos de biopolítica e biopoder estão amarrados com essa noção de população, seus fenômenos aleatórios e mecanismos de regulamentação, na medida em que não se trata apenas de uma descrição ou uma quantificação dos processos biológicos da população, mas de fazer esses processos circularem e se produzirem no jogo da norma, sendo que "uma sociedade normalizadora é o efeito histórico de uma tecnologia de poder centrada na vida" (FOUCAULT, 2001, p. 135).

Essa incursão, portanto, permite-nos problematizar aquilo que seria um fenômeno aleatório da vida da população, ou seja, a anormalidade. Sujeitos com necessidades educacionais especiais, sujeitos de risco, público-alvo, alunos e/ou sujeitos da Educação Especial, sujeitos deficientes, sujeitos com transtornos, sujeitos com altas habilidades, etc., foram narrados e produzidos como sujeitos anormais no campo de saber e poder da Educação Especial e nas suas interfaces com a Medicina Social, a Psicologia e a Pedagogia, mediante as operações da norma nos processos de identificação, classificação, hierarquização desses sujeitos pelos serviços da Educação Especial, atualmente, na perspectiva da Educação Inclusiva. Considerando o exposto, de acordo com a proposição de Rabinow e Rose (2006), o biopoder opera nos modos de subjetivação - no caso deste artigo, a subjetivação docente. A estratégia de formação de uma determinada docência para dar conta dos limites e das possibilidades da escola inclusiva e as táticas delas derivadas, como, por exemplo, a docência como prática solidária, desenvolvida na próxima seção, são exercícios, operações dessa promoção da vida num jogo neoliberal em que precisamos estar em atividade e desejar permanecer em atividade.

A manutenção do sujeito e do coletivo em atividade e o desejo de permanecer nessa situação são princípios da racionalidade política exposta por Foucault. Na obra Nascimento da biopolítica, Foucault mostra o deslocamento do liberalismo para o neoliberalismo, racionalidades políticas implicadas com a condução das condutas dos homens. Ele disserta sobre os modelos alemão, francês e americano (FOUCAULT, 2008b). O primeiro modelo, também denominado ordoliberalismo, emergente nos anos de 1948 a 1962, a partir do problema de que se governa demais, preocupou-se com o modo como a economia poderia ter uma função e um papel de estatização, de maneira a fundar efetivamente a legitimidade 
de um Estado. O segundo modelo constituiu-se a partir da difusão do modelo alemão na França, de forma lenta e com as dificuldades derivadas de uma governamentalidade estatizada, dirigista e administrativa, da crise econômica e da difusão e aplicação desse modelo alemão pelos gestores do Estado francês. O terceiro modelo desenvolveu-se nos Estados Unidos da América, nos anos de 1960, a partir dos estudos da Escola de Chicago, especialmente da obra Teoria do Capital Humano, de Theodore Schultz. Entendendo que modelos como esses perpassam o contexto brasileiro, tomamos as implicações da teoria do capital humano na educação, com algumas contribuições de autores como Gadelha (2009a, 2009b, i2010), e fazemos algumas referências ao neoliberalismo norte-americano na problematização da materialidade de pesquisa utilizada neste artigo.

De maneira geral, o neoliberalismo pressupõe "como regular o governo, a arte de governar, como [fundar] o princípio de racionalização da arte de governar no comportamento racional dos que são governados" (FOUCAULT, 2008b, p. 423). Com isso, na concepção clássica da economia, o homo oeconomicus era o homem da troca, um elemento no processo da troca. Contudo, nos moldes do neoliberalismo norte-americano, o homo oeconomicus constitui-se como um empresário, um empresário de si mesmo, "sendo ele próprio seu capital, sendo para si mesmo seu produtor, sendo para si mesmo a fonte de [sua] renda" (FOUCAULT, 2008b, p. 311). O capital humano configurado no homem, e não nos capitais reproduzíveis ou não-humanos, torna-se uma fonte de satisfações ou rendimentos futuros (SCHULTZ, 1973, p. 53). Dessa forma, o empresário de si tem a ver com os fluxos de ganhos e perdas, de maneira a agregar capital humano, de um lado, no nível do próprio sujeito, e, por outro lado, no nível da coletividade.

Pelo princípio de mercado engendrado no tecido social, estar em atividade e desejar permanecer em atividade são fatores envolvidos nos jogos de consumo e concorrência na lógica empresarial. O consumo - por exemplo, por meio da educação, da saúde, do lazer, etc. -, faz com que cada sujeito invista em si e gere renda para somar capital humano. A concorrência mostra que as relações entre os sujeitos se efetivam pelos ganhos e pelas perdas em capital humano. Esse consumo e concorrência, entretanto, necessitam fazer prosperar as unidades-empresas desses sujeitos, como no caso das escolas inclusivas. Nesse sentido, os sujeitos, mesmo sendo empresários de si, unem-se em prol dos mesmos objetivos e fins, ou dos objetivos e fins das unidades-empresas. Nessa nova forma de governamentalidade - o neoliberalismo norte-americano -, tem-se o desenvolvimento de práticas solidárias.

Na Educação Especial, no contexto educacional do Estado do Rio Grande do Sul, a formação de professores especialistas, desde 1984, ocorria no Curso de Educação Especial Habilitação Deficientes Mentais e no Curso de Educação Especial - Habilitação em Deficientes da Audiocomunicação; a prática profissional desenvolvia-se nas classes especiais ou escolas especiais e em serviços de atendimento aos deficientes auditivos e aos deficientes mentais (UFSM, 2004). Essas modalidades de atendimento, de acordo com os graus de comprometimento dos alunos da Educação Especial, promoviam a inclusão como uma possibilidade no processo de escolarização escolar desses sujeitos. 
Em 2004, esses cursos de graduação reformularam as matrizes curriculares e unificaram a formação de professores para a Educação Especial, atendendo às demandas e às exigências das políticas e das legislações promulgadas nas últimas décadas. A inclusão escolar, pela Política Nacional de Educação Especial na Perspectiva da Educação Inclusiva, tornou-se o princípio desse Curso, que, além de formar professores para classes especiais, escolas especiais e serviços especializados, passou a formar educadores especiais destinados ao atendimento dos alunos com déficit cognitivo, com dificuldade de aprendizagem e surdos nas escolas regulares. Em 2008, alterações curriculares no Curso implicaram mudanças na matriz curricular, mas não no foco da formação e/ou nas suas bases teóricas e metodológicas.

Ao lado dessa formação docente, em meados de 2007, pela organização de uma Rede Nacional de Formação de Professores em Educação Especial e por operacionalizações em nível regional, por meio do Programa de Formação Continuada de Professores na Educação Básica, uma Instituição Federal de Ensino Superior do Estado do Rio Grande do Sul passou a ofertar os Cursos de Aperfeiçoamento em Atendimento Educacional Especializado, em consonância com a referida Política Nacional. Esses Cursos de Aperfeiçoamento em AEE, com prazos de integralização dos módulos que variam entre 120, 180, 190 e 225 horas, no âmbito da pesquisa concluída que possibilitou este artigo, são tomados como uma tecnologia de governamento, ou seja, como uma tecnologia capaz de conduzir a conduta dos professores do AEE para a escola inclusiva.

Essa tecnologia de governamento torna-se capaz de movimentar estratégias e táticas na formação de professores. Que estratégia? A produção de uma subjetividade docente a partir das regulamentações e dos saberes dos cursos de formação continuada docente numa racionalidade política neoliberal. Produção de uma subjetividade docente que implica a operacionalização de táticas, dentre elas, a docência como prática solidária. Neste artigo, interessa-nos o modelo ideal de professor posto em funcionamento nos materiais didáticos relacionados à Rede Nacional de Formação Continuada de Professores na Educação Especial no nosso país. Conforme Sommer (2010, p.29), "tornar-se professor tem a ver com a apropriação de certa gramática, a inscrição em certa discursividade, o dobrar-se a uma ordem que, supostamente, define, entre outras coisas, o modelo ideal de professor". A subjetividade docente produzida na formação continuada de professores vai ao encontro, então, desse modelo ideal de professor para escola inclusiva.

\section{DAS PRÁTICAS SOLIDÁRIAS NA ESCOLA INCLUSIVA: A DOCÊNCIA PELO ATENDIMENTO EDUCACIONAL ESPECIALIZADO}

Tramando sobre as relações de consumo e concorrência, esboçamos que os empresários de si, as unidades-empresas, se uniam em prol dos mesmos objetivos e dos mesmos fins. Neste exercício de análise, que trata da docência como prática solidária, trazemos as recorrências e as singularidades que mostram o modelo ideal de professor 
produzido no processo de formação docente na Educação Especial. Nesse sentido, justificamos a utilização dos termos pactos da racionalidade política e práticas solidárias no título deste artigo e nas suas seções como pertencentes a uma relação imanente. Tal relação de imanência refere-se, no caso, à causa que se atualiza em seus efeitos; diferente da relação imediata existente entre causa e consequência (DELEUZE, 2005; BUJES, 2007).

A solidariedade diz respeito ao vínculo, à relação mútua entre sujeitos, na medida em que eles dependem uns dos outros. Castel (2009, p. 35), a partir da leitura de Émile Durkheim, diz "pacto de solidariedade, pacto de trabalho, pacto de cidadania: pensar as condições da inclusão de todos para que possam comerciar juntos, como se dizia na época do Iluminismo, isto é, 'fazer sociedade'". Utilizamos o termo com esse significado, mas atualizado, pois está implicado na racionalidade política neoliberal. A dependência, portanto, não apenas está entre os sujeitos, mas também existe em relação à prática governamental. Nessa racionalidade, residem nosso interesse e - por que não dizer - a prática de pesquisa trazida, em parte, a este artigo.

\begin{abstract}
A organização de uma sala de aula é atravessada por decisões da escola que afetam os processos de ensino e de aprendizagem. Os horários e rotinas escolares não dependem apenas de uma única sala de aula; o uso dos espaços da escola para atividades a serem realizadas fora da classe precisa ser combinado e sistematizado para o bom aproveitamento de todos; as horas de estudo dos professores devem coincidir para que a formação continuada seja uma aprendizagem colaborativa; a organização do Atendimento Educacional Especializado - AEE não pode ser um mero apêndice na vida escolar ou da competência do professor que nele atua (ROPOLI, 2010, p.10).
\end{abstract}

Esse fragmento, retirado do fascículo "A escola comum inclusiva", materializa, de certa forma, o Atendimento Educacional Especializado na escola inclusiva. Isso porque, ao assinalar os movimentos, as rotinas, as finalidades do espaço-tempo escolar, permite compreender a relação necessária e imprescindível nesse contexto. Uma relação que, como descrito acima, não depende meramente do docente do AEE nas salas de recursos multifuncionais. Uma relação que não está focada exclusivamente no serviço da Educação Especial, mas uma relação que se faz com os pares e, por isso, em regime de aprendizagem colaborativa.

A Aprendizagem Colaborativa [em Rede] (ACR) torna-se, nesse extrato e nos demais fascículos da Coleção em questão, o promotor das práticas solidárias. A ACR foi desenvolvida para um programa de formação continuada do $A E E$, na modalidade a distância, a partir da proposta metodológica da Aprendizagem Baseada em Problemas. "Seu foco é a aprendizagem colaborativa, o trabalho em equipe, contextualizado na realidade do aprendiz" (ROPOLI, 2010, p.30). Nesse sentido, a ACR envolve o trabalho com os alunos na apresentação, descrição e discussão de determinada problemática; na pesquisa em fontes bibliográficas; na proposição de soluções. O papel do docente do AEE está em elaborar um 
plano de atendimento e avaliar constantemente a aprendizagem e o desenvolvimento de seus alunos.

As redes sociais são maneiras, possibilidades de operacionalizar os pressupostos da educação inclusiva para participação e aprendizagem dos alunos na escola inclusiva. Por isso, "a formação não termina pelo curso" (ROPOLI, 2010, p. 30). A formação docente deve ter continuidade, dentre outros espaços-tempos, no próprio interior da escola mediante o contato do docente do AEE com seus pares e com a família dos alunos e comunidade em geral. Neste ponto, uma sinalização de que o Estado brasileiro precisa investir inicialmente na formação continuada dos docentes por meio de cursos de extensão, aperfeiçoamento ou especialização no AEE. Dado esse investimento inicial, chega a hora de cada um investir em si mesmo e de preocupar-se com o investimento dos outros. A inclusão escolar, como uma política de Estado, precisa funcionar. Cada um torna-se um empresário, um parceiro importante para a lógica da empresa. Todos devem estar e permanecer no jogo, no jogo de consumo, no jogo de concorrência.

As formas de empresariamento são diferentes nessa lógica da empresa. Cada empresário tem suas competências, suas atribuições, para operacionalizar a inclusão escolar. Docentes das salas regulares, docentes do AEE, famílias dos alunos. Cada um participa de uma maneira nessas redes sociais. Cada um sabe seu modo de ser e estar na promoção da inclusão escolar. Cada um aprende como organizar as unidades-empresas com as quais tem relação, para garantir o sucesso da inclusão escolar. A seguir, dois movimentos: um relativo ao docente da sala regular e ao docente do AEE; outro referente à participação das famílias na escola.

\footnotetext{
Os professores comuns e os da Educação Especial precisam se envolver para que seus objetivos específicos de ensino sejam alcançados, compartilhando um trabalho interdisciplinar e colaborativo. As frentes de trabalho de cada professor são distintas. Ao professor da sala de aula comum é atribuído o ensino das áreas do conhecimento, e ao professor do AEE cabe complementar/suplementar a formação do aluno com conhecimentos e recursos específicos que eliminam as barreiras as quais impedem ou limitam sua participação com autonomia e independência nas turmas comuns do ensino regular (ROPOLI, 2010, p.19).
}

No primeiro movimento, do fascículo "A escola comum inclusiva", as marcas de uma docência especializada. Especializada na medida em que, ao docente da sala regular, cabe o ensino das áreas do conhecimento; ao docente do $A E E$, a complementação ou suplementação da formação do aluno com necessidades educacionais especiais para que este possa participar da turma comum. Aqui, a participação está acompanhada pelas palavras autonomia e independência. Assim, a docência não serve mais para manter a dependência, e sim para promover a independência. Afinal, diferentemente das práticas pastorais, a docência, enredada na governamentalização do Estado, deve prever e prover a participação desses sujeitos do desvio nas redes de consumo e concorrência - naquilo em 
que, entre os limites colocados pelas condições de pertencimento à Educação Especial, eles têm possibilidade de participar.

Pode-se dizer, então, que tanto o docente da sala regular quanto o docente do AEE aprendem o foco de sua atuação. Ambos fazem parte dessa escola que se propõe inclusiva; ambos enfrentam o desafio constante de fazer melhor na escola inclusiva. Por isso, não basta ser e fazer de qualquer forma. Há de ser e fazer o melhor. Extremamente estranho novamente. O melhor que o empresário de si carrega como princípio do autoinvestimento e dos investimentos nos outros. O melhor que leva o empresário de si a procurar parceiros solidários para este propósito da inclusão escolar. A solidariedade parece inscrever os indivíduos na lógica da empresa.

\footnotetext{
É também imprescindível o envolvimento dos familiares e do próprio aluno para que a tomada de decisão sobre o melhor recurso leve em consideração aspectos relevantes percebidos por quem convive diariamente com os problemas e já possui uma experiência de vida sobre soluções viáveis e outras que não darão certo (GIACOMINI, 2010, p.36).
}

Nesse segundo movimento, referente ao fascículo "Orientação e mobilidade, adequação postural e acessibilidade espacial", tem-se a importância da família na unidadeempresa. O conhecimento do aluno, conhecimento este anterior e exterior à escola, e o estabelecimento de modos para trazer a família para este contexto mobilizam os docentes do AEE. Eles precisam agregar outros elementos de capital humano na ação pedagógica desenvolvida com os sujeitos da Educação Especial. Elementos de capital humano diferentes daqueles provindos dos investimentos da escolarização, mas igualmente importantes para promover fontes de renda futura. Elementos de capital humano que, conforme Foucault (2008b, p.311-312), os neoliberais consideram

\footnotetext{
muito mais numerosos do que o simples aprendizado escolar ou que o simples aprendizado profissional. (...) Tempo passado, cuidados proporcionados, o nível de cultura dos pais também - porque se sabe muito bem, justamente, que, para um mesmo tempo passado, pais cultos vão formar um capital humano, para a criança, muito mais elevado do que se não tiverem o mesmo nível de cultura -, o conjunto dos estímulos culturais recebidos por uma criança: tudo isso vai constituir elementos capazes de formar um capital humano.
}

Esses elementos de capital humano, somados àqueles que provêm dos processos de escolarização, podem garantir práticas de governamento capazes de, ao gerenciar o risco, potencializar os processos de participação e aprendizagem dos alunos da Educação Especial. A família, considerando as especificidades presentes em cada grupo familiar, como organização familiar, traços comportamentais, nível socioeconômico e religião, entre outros, em um tênue processo de negociação com a escola inclusiva e o docente do $A E E$, envolve-se ou não com o propósito da inclusão de seus membros na escola. A escola inclusiva e os docentes do AEE, por isso, precisam do envolvimento da família para esse estado permanente de inclusão que se deseja e que se ensina esses sujeitos a desejar. 
Agora, aqueles que poderiam denominar um terceiro movimento, que, mesmo não estando anunciado nesta seção, perpassa a materialidade da pesquisa deste artigo: os outros profissionais envolvidos com a inclusão escolar. Profissionais estes que, derivando das formações médicas, psicológicas e áreas afins, integram as redes sociais desses outros polivalentes responsáveis pelos sujeitos com deficiência, transtornos globais do desenvolvimento ou altas habilidades/superdotação. São os profissionais conhecidos como especialistas. Como expõe o extrato do fascículo "Recursos pedagógicos acessíveis e comunicação aumentativa e alternativa" a seguir:

O professor do AEE, que deve estar em contato direto com o aluno, pode coordenar este processo, solicitando à família, aos professores da escola comum e aos outros profissionais que atendem a esse aluno todas as informações que entender necessárias (SARTORETTO, 2010, p.50).

A polivalência presente na formação continuada pelo AEE não nega a expertise. $O$ docente do AEE também congrega uma expertise. Mais do que isso, na prática pedagógica, o material didático em questão prevê que ele necessitará de outras expertises para consolidar redes de apoio. Então, profissionais são convidados a estar juntos no processo de inclusão dos alunos com deficiência intelectual, com deficiência visual, surdos, surdocegos, com deficiência múltipla, transtornos globais do desenvolvimento e altas habilidades/superdotação.

Nesses três movimentos, a ACR desenvolve-se por intermédio das redes sociais. A docência do $A E E$, exercida com práticas solidárias, visa a promover a participação e a aprendizagem dos alunos na escola inclusiva. Nesse contexto, com esse objetivo, com essa finalidade, os profissionais e as famílias envolvidas, desde que sistematizem suas ações, podem garantir o sucesso da inclusão escolar. O Plano de Ação Pedagógica, conforme Cursos do AEE ofertados pela IFES mencionada anteriormente, ou o Plano de Trabalho, de acordo com os fascículos da Coleção, tem essa função de conhecer os alunos, identificar os limites no processo de aprendizagem, desenvolver metodologias e recursos acessíveis para promover a aprendizagem, avaliar constantemente o processo de aprendizagem do aluno e a ação pedagógica desenvolvida com ele.

A sistematização do Plano de Ação Pedagógica, plano este que deve ser organizado pelo docente em formação no AEE após os módulos que tratam das deficiências, dos transtornos globais do desenvolvimento e das altas habilidades/superdotação, pressupõe o mapeamento dos alunos do desvio. Tal mapeamento torna-se necessário para efetivar a ação pedagógica. Nesta, qual a finalidade? Obter benefícios, beneficiários - alunos, escolas, professores e comunidade.

O fascículo "Surdocegueira e deficiência múltipla" indica três grandes áreas que foram e podem ser organizadas no Plano de Trabalho do AEE: 
I - O AEE individual, implicando principalmente meu trabalho especializado com a aluna;

II - O AEE coletivo, envolvendo seus colegas, a professora da sala de aula e o trabalho com os demais profissionais da escola; e

III - Articulação com instituições e profissionais externos à escola (Prefeitura Municipal, Secretarias da Saúde, Educação, Assistência Social), com a família e com o entorno da escola (BOSCO, 2010, p.39).

Esse extrato mostra que o docente do AEE deve partir do trabalho especializado e, em seguida, envolver os colegas e os demais profissionais da educação da escola, bem como ampliar as ações pedagógicas com a parceria de setores específicos do serviço público, da família e da comunidade. Os objetivos da inclusão escolar servem, nesse momento, às ações no nível individual e àquelas que devem comprometer e mobilizar todos no processo de inclusão.

Dessa forma, as práticas solidárias servem ao Estado. Servem na medida em que, por essas práticas sistemáticas, os docentes das salas regulares, os docentes do $A E E$, os próprios sujeitos da Educação Especial, as famílias, os outros profissionais da educação e os setores da comunidade podem assumir-se como empresários e, com isso, como parceiros da lógica empresarial. Servem porque, pelas práticas solidárias, o Estado divide sua responsabilidade e, assim, tem como garantia o sucesso da inclusão escolar.

Considerando-se isso, o homo oeconomicus, indicado na seção anterior, será aquele indivíduo governamentalizável pelo Estado e pelas práticas de governamento. "o homo oeconomicus é a interface do governo e do indivíduo. E isso não quer dizer de forma alguma que todo indivíduo, todo sujeito, é um homem econômico" (FOUCAULT, 2008b, p. 346). 0 homo oeconomicus, o empresário de si, será aquele capturado e mobilizado pelas ações do Estado. Estas são ações que, como demonstramos até o momento, operacionalizam a lógica empresarial, inclusive, nos espaços-tempos escolares, por meio das redes sociais, dos parceiros. As práticas solidárias inscrevem todos - nós, você - na lógica da empresa. Como relata Traversini (2006, p.82), em relação ao Programa Alfabetização Solidária (PAS), "essa prática levava os sujeitos solidários a se tornarem comprometidos com o sucesso de si próprios, dos outros e do Estado".

Nesse sentido, a economia política entra em jogo ao lado de outros campos de saber e poder - a Medicina, a Psicologia, a Pedagogia - para "estudar o trabalho exercido pelos indivíduos como uma conduta econômica, e [...] tentar entender como essa conduta é praticada, racionalizada e calculada por aquele que exerce" (GADELHA, 2009b, p. 176). Por isso, a partir dos estudos da economia política, desses estudos que tratam das racionalidades políticas implicadas na condução das condutas, o docente do AEE, em parceria com outros sujeitos, operacionaliza e participa da lógica empresarial da escola inclusiva. Trata-se, de qualquer modo, de focar esse homo oeconomicus como o indivíduo que reconhece a si e ao outro como um empresário, a fim de, mediante práticas solidárias, produzir fluxos de renda, ganhos, benefícios à escola inclusiva, ao Estado brasileiro. 
Esse empresário de si e comprometido com os outros nas práticas solidárias perpassa o modelo ideal de professor produzido pela Rede Nacional de Formação Continuada de Professores na Educação Especial no Brasil. O mesmo docente que aprende a querer modificar-se também deve colocar-se à disposição desses outros - alunos, profissionais da educação, família, comunidade. Esses outros, igualmente empresários de si, são participantes da lógica empresarial. Não se trata de uma revitalização do professorpastor, nem mesmo algo posto em funcionamento exclusivamente por um mecanismo disciplinar. $\mathrm{O}$ autoinvestimento do docente do AEE e o investimento nesse outro decorre de uma estratégia em benefício do próprio docente do $A E E$, de sua própria satisfação e do sucesso da escola inclusiva. E, nessa perspectiva, trata-se de uma medida de segurança que, associada ao mecanismo disciplinar e ao pastorado - sim, pois a segurança não anula a disciplina ou a pastoral, mas as atualiza -, coloca tudo e todos como alvos e efeitos da governamentalização do Estado.

Essa lógica, tramada numa racionalidade neoliberal, constitui um modelo ideal de professor para a escola inclusiva. Algum pêndulo, além das práticas solidárias, poderia ser mais eficaz para esse modo de subjetivação, para esse investimento biopolítico? Propomos que não, uma vez que essa racionalidade política neoliberal, seus dispositivos, suas tecnologias, fazem

\footnotetext{
um uso estratégico da educação (familiar, escolarizada, técnico-profissional, universitária etc.) e da pedagogização das novas tecnologias e práticas de gestão, vistas como fontes fundamentais de investimentos em capital humano, para radicalizar o processo de empresariamento da sociedade, tomando o mercado como princípio de inteligibilidade e a concorrência como princípio de formalização e como ancoragem mestra (GADELHA, i2010, p.23-24).
}

A educação, especialmente a escolarização, acompanha o docente do AEE e os demais sujeitos. Melhor, os processos de escolarização dependem desses sujeitos para funcionar e produzir efeitos. Do mesmo jeito, a gestão - esse princípio que mobiliza as práticas solidárias nas escolas inclusivas - coloca em operação a lógica empresarial, marcada pelo mercado - como o agente que une a economia política com a prática governamental - e pelos processos de consumo e concorrência dele derivados. O mercado não está longe, nem se constitui como uma instância supra. O mercado, costurado à razão de Estado, à governamentalização do Estado, está em cada um. Os indivíduos são capturados e, nessa captura consentida, uma vez que o poder envolve negociação, produzem isso que tomamos como mercado, isso que tomamos como Estado. A formação docente pelo $A E E$, então, produz um modelo ideal de professor para a escola inclusiva e o faz pelos processos de subjetivação docente.

\section{SOBRE A CONSTÂNCIA DA PROBLEMATIZAÇÃO}

A Política Nacional de Educação Especial na Perspectiva da Educação Inclusiva e legislações vigentes que, nas últimas décadas, promoveram a relação da Educação Inclusiva com a Educação Especial no processo de escolarização dos alunos com necessidades 
educacionais especiais provocaram mudanças na formação continuada de professores em Educação Especial. Dessa maneira, não basta tomarmos esse processo formativo como centralidade dos investimentos na agenda nacional. Os investimentos em nível nacional e regional nessa formação continuada produzem efeitos na forma como os professores do AEE constituem-se como sujeitos nas relações consigo mesmos e com os outros nas ações pedagógicas, nos modos de subjetivação docente.

Em nível nacional, a Rede Nacional de Formação Continuada de Professores na Educação Especial, por meio de regulamentações e materiais didáticos, propõe os programas institucionais e os cursos do AEE. Nesse sentido, as orientações pedagógicas dessa Rede Nacional procuram mobilizar e operacionalizar determinados conhecimentos, recursos, técnicas e atitudes na docência na Educação Especial. Em nível regional, as orientações pedagógicas que balizam a Rede Nacional são incorporadas, por exemplo, no Programa de Formação Continuada de Professores na Educação Básica implantado na IFES mencionada anteriormente. Esta implementa Cursos de Aperfeiçoamento que, pela curta duração e massiva informação, devem formar um professor para dar conta dos limites e das possibilidades da escola inclusiva. Por isso, o exercício analítico empreendido neste artigo desenvolveu-se em consonância com a racionalidade política neoliberal.

Neoliberalismo norte-americano no contexto brasileiro que, pela lógica da empresa, imprime o empresariamento de si e a solidariedade nessa formação continuada para contribuir com a inclusão escolar, uma política de Estado. Melhor, a política de um Estado governamentalizado. O AEE, então, constitui-se como uma tecnologia de governamento docente capaz de movimentar estratégias e táticas na formação de professores - a estratégia de produção de uma subjetividade docente a partir das regulamentações e dos saberes dos cursos de formação continuada docente, com a operacionalização de táticas. Neste caso, a docência como uma prática solidária.

Nas práticas solidárias, os docentes das salas regulares, os docentes do $A E E$, os próprios sujeitos da Educação Especial, as famílias, os outros profissionais da educação e os setores da comunidade estão envolvidos na política de Estado. No processo de governamentalização, tudo e todos são alvos e efeitos desse Estado; dividimos nossas responsabilidades, somamos nossas ações em prol da inclusão. A racionalidade neoliberal norte-americana produz um modelo ideal de professor para a escola inclusiva no Brasil. 0 sucesso da inclusão escolar continua a ser influenciado pelos docentes do AEE e pela organização da Educação Especial dentro das escolas inclusivas. E, para finalizar este artigo e possibilitar a constância desta problematização, registramos novamente a pergunta: algum pêndulo, além das práticas solidárias, poderia ser mais eficaz para esse modo de subjetivação, para esse investimento biopolítico? 


\section{REFERÊNCIAS}

BOSCO, Ismênia Carolina Mota Gomes [et. al.]. Surdocegueira e deficiência múltipla. Brasília, DF: Ministério da Educação, Secretaria de Educação Especial, Universidade Federal do Ceará, 2010. 48p. (Coleção A Educação Especial na Perspectiva da Inclusão Escolar)

BUJES, Maria Isabel Edelweiss. Descaminhos. In: COSTA, Marisa Vorraber (org.). Caminhos investigativos II: novos modos de pensar e fazer pesquisa em educação. Rio de Janeiro, RJ: Lamparina, 2007, p. 13-34.

CASTEL, Robert. As metamorfoses da questão social: uma crônica do salário. Petrópolis, RJ: Vozes, 2009. 611p.

DELEUZE, Gilles. Foucault. Tradução de Claudia Sant' Anna Martins. São Paulo, SP: Brasiliense, 2005. $142 \mathrm{p}$.

FOUCAULT, Michel. Segurança, território e população. Curso dado no Collège de France (1977-1978). Tradução de Eduardo Brandão. São Paulo, SP: Martins Fontes, 2008a. 572 p. (Coleção tópicos)

. Nascimento da biopolítica. Curso dado no Collège de France (1978-1979). Tradução de Eduardo Brandão. São Paulo, SP: Martins Fontes, 2008b. 474 p. (Coleção tópicos)

. Em defesa da sociedade. Curso dado no Collège de France (1975-1976). Tradução de Maria Ermantina Galvão. São Paulo, SP: Martins Fontes, 2005. 382 p. (Coleção tópicos)

História da Sexualidade I: a vontade de saber. Tradução de Maria Thereza da Costa Albuquerque e J. A. Guilhon Albuquerque. Rio de Janeiro, RJ: Graal, 2001. 152 p.

GADELHA, Sylvio. Biopolítica, governamentalidade e educação: introdução e conexões a partir de Michel Foucault. Belo Horizonte, MG: Autêntica, 2009. 240 p. (Educação: Experiência e Sentido)

Govenamentalidade (neo)liberal, concorrência, empreendedorismo e educação: uma abordagem foucaultiana. [S.I.: s.n.], i2010. 30p.

. Governamentalidade neoliberal, Teoria do Capital Humano e empreendedorismo. In: Revista Educação \& Realidade, v.34, n. 02, p.171-186, mai./ago. 2009b.

GIACOMINI, Lília [et. al.]. Orientação e mobilidade, adequação postural e acessibilidade espacial. Brasília, DF: Ministério da Educação, Secretaria de Educação Especial, Universidade Federal do Ceará, 2010. 44p. (Coleção A Educação Especial na Perspectiva da Inclusão Escolar) 
RABINOW, Paul; ROSE, Nikolas. O conceito de biopoder hoje. In: Política e Trabalho. Revista de Ciências Sociais, n 24, p. 27-57, abr. 2006.

ROPOLI, Edilene Aparecida [et. al.]. A escola comum inclusiva. Brasília, DF: Ministério da Educação, Secretaria de Educação Especial, Universidade Federal do Ceará, 2010. 48p. (Coleção A Educação Especial na Perspectiva da Inclusão Escolar) SARTORETTO, Mara Lúcia [et. al.]. Recursos pedagógicos acessíveis e comunicação aumentativa e alternativa. Brasília, DF: Ministério da Educação, Secretaria de Educação Especial, Universidade Federal do Ceará, 2010. 64p. (Coleção A Educação Especial na Perspectiva da Inclusão Escolar)

SCHULTZ, Theodore William. O capital humano: investimentos em educação e pesquisa. Tradução de Marco Aurélio de Moura Matos. Rio de Janeiro, RJ: Zahar, 1973. 250 p.

SOMMER, Luís Henrique. Práticas de produção da docência: uma análise sobre literatura de formação de professores. In: Anais do XV ENDIPE - Encontro Nacional de Didática e Prática de Ensino: Convergências e tensões no campo da formação e do trabalho docente: políticas e práticas educacionais. Belo Horizonte, MG, 2010, p. 28-37.

TRAVERSINI, Clarice Salete. Debite um analfabeto no seu cartão: a solidariedade como estratégia para alfabetizar a população e desresponsabilizar o Estado. In: Educação em Revista, Belo Horizonte, MG, v.43, p.73-93, jun. 2006.

UNIVERSIDADE FEDERAL DE SANTA MARIA. Projeto Pedagógico do Curso de Educação Especial - Licenciatura. Santa Maria, RS: Pró-Reitoria de Graduação, 2004.

\footnotetext{
${ }^{1}$ Revisado por Lene Belon Ribeiro.
} 